\title{
TRH Neurons and Thyroid Hormone Coordinate the Hypothalamic Response to Cold
}

\author{
Zhi Zhang $^{\mathrm{a}}$ Anita Boelen $^{\mathrm{a}}$ Andries Kalsbeek $^{\mathrm{a}, \mathrm{b}}$ Eric Fliers $^{\mathrm{a}}$

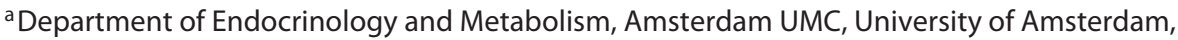 \\ Amsterdam, The Netherlands; ${ }^{b}$ Hypothalamic Integration Mechanisms, Netherlands Institute for \\ Neuroscience, Royal Netherlands Academy of Arts and Sciences, Amsterdam, The Netherlands
}

\section{Keywords}

Thyroid hormone - Thyrotropin-releasing hormone · Hypothalamus · Thermogenesis · Cold · Brown adipose tissue

\footnotetext{
Abstract

Thyroid hormone ( $\mathrm{TH}$ ) plays a key role in regulating body temperature in mammals. Cold exposure stimulates the hypothalamus-pituitary-thyroid (HPT) axis at the hypothalamic level by activating hypophysiotropic thyrotropin-releasing hormone (TRH)-producing neurons, ultimately resulting in increased plasma TH concentrations. Importantly, the local TH metabolism within various cold-responsive organs enables tissue-specific action of TH on heat production and adaption to cold independently of the circulating $\mathrm{TH}$ levels. In addition to these neuroendocrine effects, TRH neurons in the hypothalamus also have neural connections with brown adipose tissue (BAT), probably contributing to regulation of thermogenesis by the autonomic nervous system. Recent studies have demonstrated that intrahypothalamic $\mathrm{TH}$ has profound
}

metabolic effects on BAT, the liver, and the heart that are mediated via the autonomic nervous system. These effects originate in various hypothalamic nuclei, including the paraventricular nucleus (PVN), the ventromedial nucleus, and recently reported neurons in the anterior hypothalamic area, indicating a potential central function for TH on thermoregulation. Finally, although robust stimulation of the thermogenic program in BAT was shown upon $\mathrm{TH}$ administration in the ventromedial hypothalamus, the physiological relevance of these neurally mediated effects of $\mathrm{TH}$ is unclear at present. This review provides an overview of studies reporting the role of $\mathrm{TH}$ in cold defense, with a focus on recent literature evidencing the centrally mediated effects of TRH and $\mathrm{TH}$.

(C) 2018 European Thyroid Association Published by S. Karger AG, Basel

\section{Introduction}

Thyroid hormone (TH) has been known to be crucially involved in thermoregulation for many decades. Hypothyroid patients or experimental animals with low $\mathrm{TH}$ levels have a decreased metabolic rate and an im-

\section{KARGER}

E-Mail karger@karger.com www.karger.com/etj (c) 2018 European Thyroid Association Karger Published by S. Karger AG, Basel Open access

This article is licensed under the Creative Commons AttributionNonCommercial-NoDerivatives 4.0 International License (CC BYNC-ND) (http://www.karger.com/Services/OpenAccessLicense) Usage and distribution for commercial purposes as well as any distribution of modified material requires written permission.
Eric Fliers

Department of Endocrinology and Metabolism, Amsterdam UMC University of Amsterdam, Meibergdreef 9

NL-1105AZ Amsterdam (The Netherlands)

E-Mail e.fliers@amc.uva.nl 
paired cold tolerance. Conversely, an excess of TH induces increased metabolic rate and heat production [13]. Circulating TH levels are maintained within a narrow physiological range as a result of a negative feedback action in the context of the hypothalamus-pituitary-thyroid (HPT) axis $[4,5]$. The thyroid gland produces thyroxine (T4) and, to a lesser extent, the biologically active $\mathrm{TH} 3,3^{\prime}, 5$-triiodothyronine (T3). Of note, in many tissues, T4 is converted into T3 by the enzyme type 2 deiodinase (D2), but T4 and T3 can also be inactivated by the enzyme type 3 deiodinase (D3) [6]. The relative contribution of these enzymes enables a local regulation of T3 availability which is to a certain extent independent of the circulating TH concentrations $[6,7]$. This has been shown to be of physiological importance during specific environmental conditions such as illness [8], fasting [9], and cold exposure [10]. Cold exposure significantly activates the HPT axis, with increased thyrotropin-releasing hormone (TRH) synthesis, thyroid-stimulating hormone (TSH) release, and serum TH concentrations together coordinating an increase in thermogenesis and cold adaption. However, only little is known about the mechanisms that regulate cold-induced thermogenesis in the context of TH and TRH. Recent studies have advanced our understanding of TRH- and $\mathrm{TH}$-mediated regulation of the metabolism critically involved in cold defense, including liver glucose and lipid production, brown adipose tissue (BAT) thermogenesis, and browning of white adipose tissue (WAT) as well as vasomotorcontrolled heat dissipation. A significant part of these studies indicates that $\mathrm{TH}$ regulates energy metabolism by its effects within the hypothalamus. A number of hypothalamic nuclei including the paraventricular nucleus $(\mathrm{PVN})$, the ventromedial nucleus, the preoptic area (POA), and the arcuate nucleus (ARC) have been shown to mediate the intrahypothalamic effects of T3 on a variety of key metabolic functions [11]. Of note, a subpopulation of neurons in the anterior hypothalamic area relies on $\mathrm{T} 3$ signaling via $\mathrm{TH}$ receptor (TR) a during development for proper neural regulation of cardiovascular function in adulthood [11, 12]. Moreover, subsets of TRH neurons within the PVN are responsible for dynamic HPT axis set point regulation, and they also contribute to neural control of feeding, locomotor activity, and body temperature [13]. Therefore, both hypothalamic TRH and TH are essential for energy balance and maintenance of homeostasis upon cold exposure.

\section{Effects of Cold Exposure on the HPT Axis}

Cold exposure activates the HPT axis at different levels. Cold exposure induces a marked increase in TRH expression in the PVN and stimulates its release to the median eminence (ME) [14-16]. The TRH neurons involved in HPT axis regulation are the so-called hypophysiotropic TRH neurons, which are groups of parvocellular neurons located in the medial and periventricular portions of the hypothalamic PVN [13]. In humans, the distribution of TRH neurons is mainly restricted to the dorsocaudal portion of the nucleus [17]. Axons from hypophysiotropic TRH neurons project to the hypothalamic ME, where TRH is released into the portal system, thereby reaching the anterior pituitary. TRH stimulates pituitary thyrotrophs to secrete TSH which in turn stimulates $\mathrm{T} 3$ and $\mathrm{T} 4$ production and secretion by the thyroid gland [4]. However, the cold-induced increase in TRH synthesis and TH levels in the circulation is transient and short-lived, as TRH mRNA expression is increased in the PVN already within $1 \mathrm{~h}$ after the start of cold exposure; it returns to control levels after $2 \mathrm{~h}$, while the circulating T3 levels peak after $2 \mathrm{~h}$ and then start to return to control values [15]. This short timeframe is in line with our recent observations in healthy men [18]. Thus, the increase in hypothalamic TRH within the PVN and circulating $\mathrm{TH}$ levels is very likely to contribute to the initiation of the thermogenic response. Interestingly, cold activates not only the hypophysiotropic TRH neurons that stimulate anterior pituitary TSH release but also the nonhypophysiotropic TRH neurons in the PVN $[19,20]$. These nonhypophysiotropic TRH neurons project to various brain areas, exerting separate and diverse actions on energy homeostasis and BAT thermogenesis as described later on $[13,21]$.

\section{Effects of TH on Adaptive Thermogenesis and Heat Conservation}

Homoeothermic animals have developed precise thermogenic mechanisms to keep a steady body temperature in the face of generally colder environmental habitats, including physiological and behavioral responses to generate or preserve heat. TH affects both obligatory thermogenesis, the involuntary thermogenic process due to basal metabolic activity, and adaptive thermogenesis that refers to additional heat production when obligatory thermogenesis is insufficient. As a master regulator of energy metabolism, $\mathrm{TH}$ is involved in all of the above 
mechanisms for cold defense. TH increases obligatory thermogenesis by boosting the basal metabolic rate, and it is also required for adaptive thermogenesis in thermogenic organs including BAT (though it is not sufficient by itself), WAT, and skeletal muscle [22].

The primary organ for adaptive thermogenesis in rodents is BAT, a specialized adipose tissue capable of heat production [23]. The significant effect of TH directly on BAT thermogenesis has been extensively demonstrated [for review, see 22, 24]. Pioneer studies by Silva and Larsen [25] first indicated that sympathetic activation of BAT by cold exposure increases D2 activity in BAT, resulting in an increase in local T3 concentrations independently of the circulating $\mathrm{TH}[10,26,27]$. In line with this, D2 knockout mice display impaired BAT thermogenesis and hypothermia upon cold exposure [26, 28]. Synergistically with adrenergic signaling, increased T3 further accelerates transcriptional induction of genes essential for lipogenesis, mitochondrial biogenesis and thermogenesis, including uncoupling protein 1 (Ucp1) $[27,29]$. UCP1 is a protein expressed in BAT that increases proton leakage during electron transport, thereby shifting energy oxidation from ATP production to the release of heat [30]. Although T3 increases Ucp1 expression through TR $\beta$, both types of TR are required for the full program of BAT thermogenesis [31]. Additionally, a recent study indicated that adipocyte fatty acid-binding protein $(\mathrm{A}-\mathrm{FABP})$ is involved in cold- and $\mathrm{TH}$-induced BAT thermogenesis [32].

In addition to BAT, emerging evidence also indicates a substantial role of white or beige adipose tissue in coldand TH-stimulated thermogenesis [24]. T3 treatment in human white adipocytes resulted in increased mitochondrial biogenesis and oxygen consumption rates as well as Ucp1 expression independently of TR $\beta$ [33]. TR activation by GC-1, a TR $\beta$-specific agonist, induced browning of WAT and increased thermogenesis in subcutaneous WAT independently of BAT both in vitro and in vivo [34]. Interestingly, intracerebroventricular (ICV) or ventromedial hypothalamus (VMH)-specific administration of T3 increased brightening/beiging of WAT [35], suggesting central control of TH on WAT thermogenesis. Studies in LXR- $\alpha /$ LXR- $\beta$-deficient mice revealed increased Ucp1 expression in subcutaneous WAT, which resulted from activation of TRH neurons in the PVN, stimulating secretion of TSH and thereby increasing circulating TH concentrations [36, 37]. Together these studies indicate an important role for $\mathrm{TH}$ regulation of WAT thermogenesis during cold exposure. However, another recent study paradoxically showed that both hyperthyroidism and hypothyroidism increased WAT browning in mice [38]. Since the hypothyroid mice showed reduced BAT activity, the authors hypothesized compensatory WAT browning in response to decreased heat production due to BAT inactivity, as suggested previously by others [39].

Similar to regulation of BAT and WAT thermogenesis, TH is critical for an optimal thermogenic response in skeletal muscle. Heat production is higher in euthyroid skeletal muscle compared to hypothyroid muscle. T3 induced production of UCP3, which is the isoform of uncoupling protein primarily expressed in skeletal muscle, is associated with an increased energy expenditure in skeletal muscle [40]. Nevertheless, T3 treatment did increase the resting metabolic rate in $U c p 3$ knockout mice similarly to wild type mice, suggesting that additional pathways, including the sarcoplasmic reticulum $\mathrm{Ca}^{2+}$ ATPase (SERCA1) uncoupling mechanism [41], may be involved in $\mathrm{TH}$-induced skeletal muscle thermogenesis [42].

Cold also triggers a reduced rate of heat exchange between the skin and the environment by decreasing the skin blood flow via cutaneous vasoconstriction [43]. The effects of vasomotion on thermoregulation during cold are prominent and also tightly regulated by $\mathrm{TH}$. Mice with a heterozygous mutation in TR $\alpha$ exhibited impaired tail vasoconstriction resulting in a lower nocturnal body temperature despite compensatory BAT hyperactivity. This defective tail heat dissipation was restored after T3 treatment, indicating a key role of $\mathrm{TH}$ in heat preservation by tail vasoconstriction [44]. A schematic representation of $\mathrm{TH}$ regulated thermoregulation is shown in Figure 1.

\section{Effects of TRH on BAT Thermogenesis}

\section{Hypothalamic TRH Controls BAT Thermogenesis}

TRH in the PVN is best known for its regulation of the HPT axis set point, thereby affecting thermoregulation and energy metabolism. However, the nonhypophysiotropic TRH neurons also play a key role in thermoregulation through their projections to other brain areas. ICV administration of TRH to Syrian hamsters was shown to increase the BAT activity and core temperature without affecting circulating TH levels. These effects were attenuated by sympathetic denervation of BAT [45], indicating a central effect mediated via the sympathetic nervous system (SNS). In addition, a number of studies have shown that TRH injections into the 


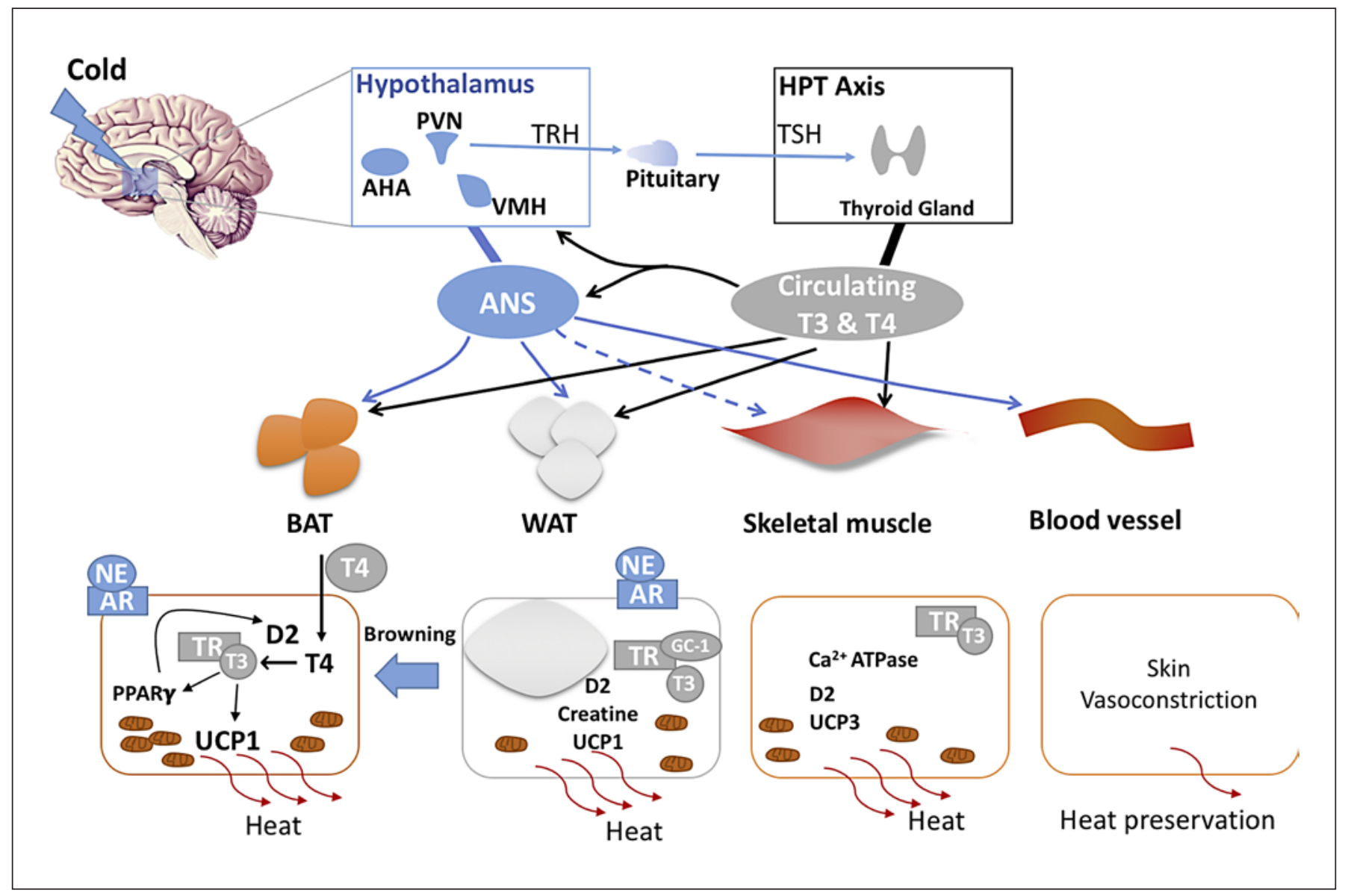

Fig. 1. Combined central and systemic regulation of thermogenesis by TRH and thyroid hormone. AHA, anterior hypothalamic area; ANS, autonomic nervous system; NE, norepinephrine; AR, adrenergic receptor; GC-1, thyroid hormone receptor agonist.

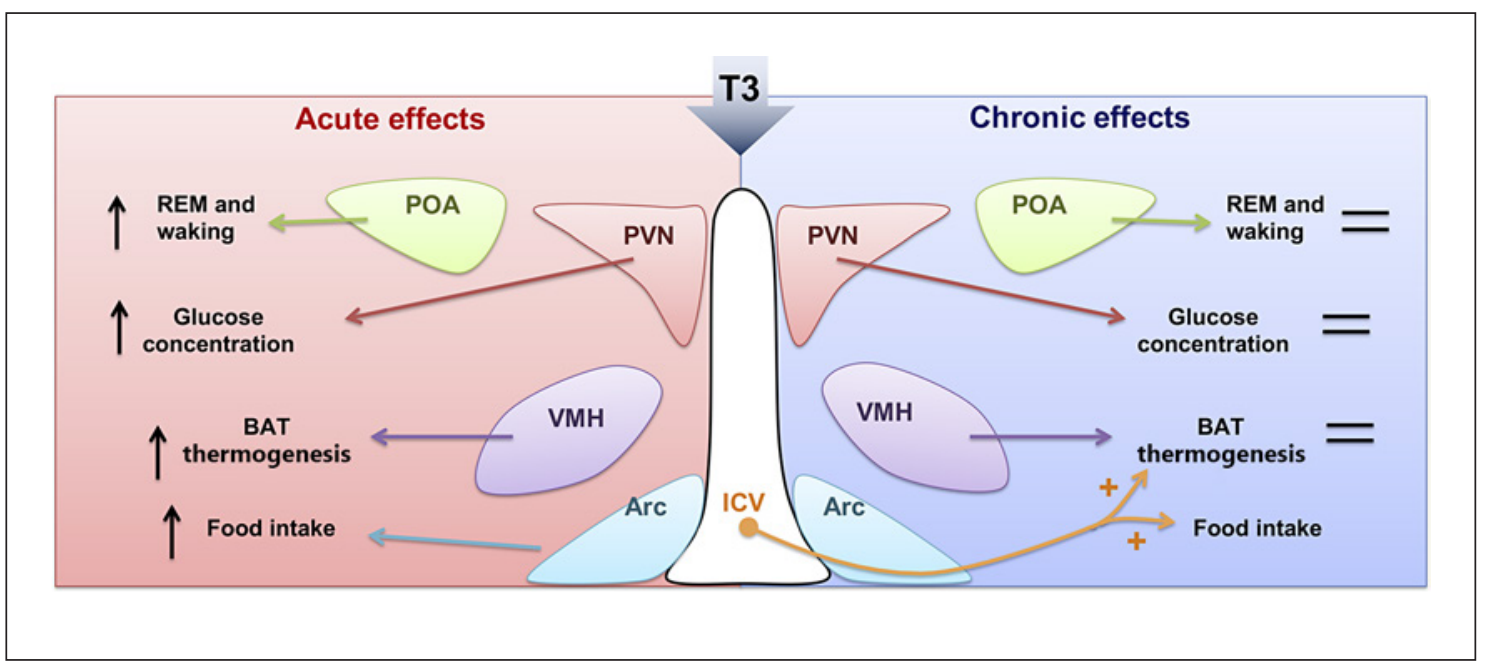

Fig. 2. Summary of the reported differential effects of acute vs. chronic intrahypothalamic T3 administration on energy metabolism. REM, rapid eye movement. With permission from Zhang et al. [11]. 
POA, a well-recognized primary site for thermoregulation, cause hyperthermia in rats $[46,47]$. It has been demonstrated that TRH inhibits heat-sensitive neurons and activates cold-sensitive neurons in the POA [48], a mechanism resulting in increased heat production and conservation. However, ablation of the POA did not block TRH antagonism of pentobarbital-induced hypothermia, suggesting that sites other than the POA may also mediate the thermogenic effect of TRH [49]. Indeed, TRH injections directly into other distinct hypothalamic areas including the dorsal medial hypothalamus and the VMH have also been shown to induce hyperthermia [45]. Interestingly, within the hypothalamus, short-term cold exposure activates TRH neurons exclusively in the PVN [16], including both hypophysiotropic and nonhypophysiotropic TRH neurons [14, 50]. Moreover, the PVN is one of the hypothalamic regions containing second-order neurons to be infected after pseudorabies virus retrograde tracing from interscapular BAT, representing a neuroanatomical substrate for hypothalamic modulation of BAT function [51, 52]. Therefore, in addition to hypophysiotropic TRH neurons involved in the endocrine response via the HPT axis, also nonhypophysiotropic TRH neurons in the PVN probably contribute to the cold response via an autonomic relay. The concept that TRH release in the PVN plays an important role in control of thermogenesis and energy mobilization during cold exposure was supported by recent observations in rats exposed to either cold or TRH microdialysis in the PVN for $2 \mathrm{~h} \mathrm{[21].}$ Cold exposure increased body temperature, locomotor activity, and plasma corticosterone concentrations, while blood glucose concentrations remained unchanged. TRH administration in the PVN also promptly increased body temperature, locomotor activity, and plasma corticosterone concentrations. In addition, TRH administration in the PVN increased blood glucose concentrations and endogenous glucose production (EGP). Further examination showed increased gluconeogenesis in the liver and lipolysis in BAT, both after cold exposure and after TRH administration. Thus, TRH administration in the PVN largely mimicked the metabolic and behavioral changes induced by cold exposure, indicating a potential link between TRH release in the PVN and cold defense [21].

\section{Systemic TRH Administration Activates BAT in Humans}

The involvement of TRH in the cold response is also indicated by the fact that TRH knockout mice showed cold intolerance, which could not be corrected with TH supplementation $[9,36,53]$. A recent study by Heinen et al. [18] evaluated the effect of an intravenous bolus injection of TRH on BAT thermogenesis in humans in a randomized controlled trial using ${ }^{18} \mathrm{~F}-\mathrm{FDG}$ PET. They showed that some, but not all, healthy volunteers who were preexposed to mild cold displayed a clear increase in ${ }^{18} \mathrm{~F}-\mathrm{FDG}$ uptake in BAT after TRH administration compared to placebo. This increase in ${ }^{18} \mathrm{~F}-\mathrm{FDG}$ uptake was not paralleled by any changes in plasma $\mathrm{TH}$. The exact mechanism of BAT activation induced by systemic TRH is still unknown; however, evidence from animal studies suggests a central effect of TRH acting through the hypothalamus $[45,46]$.

\section{Systemic Effects of Intrahypothalamic TH}

The thermoregulatory system in mammals engages coordination of various physiologic responses upon cold exposure, including energy mobilization and heat production and preservation. Although TH have major effects on energy metabolism and thermoregulation by directly acting on peripheral organs such as adipose tissue and muscle, an increasing number of studies have demonstrated neural effects of TH acting within the hypothalamus. The hypothalamus contains a number of nuclei containing anatomically and functionally clustered neurons that sense and integrate metabolic information from the body. Some of these nuclei project to hypothalamic preautonomic motor neurons, enabling a fast response via an autonomic outflow to peripheral organs [54]. TH receptors, transporters, and deiodinases are widely expressed in the hypothalamus, providing a substrate for TH to regulate the energy metabolism via intrahypothalamic effects [55-57].

\section{T3 in the PVN Controls Glucose Metabolism}

Increased energy expenditure during cold is accompanied by increased glucose and fatty acid oxidation. Thyrotoxicosis is known to increase hepatic glucose production (EGP) as well as lipolysis and proteolysis, thereby providing substrates required for the concomitant increase in energy expenditure $[58,59]$. Intriguingly, thyrotoxicosis has also been associated with increased activity of the SNS [60]. Earlier studies from our lab demonstrated that stimulation of EGP by thyrotoxicosis was mediated in part via the SNS, as selective hepatic sympathetic denervation diminished the increase in EGP induced by thyrotoxicosis [61]. These neurally mediated 
effects of T3 on glucose were shown to be mediated by the hypothalamus. Local administration of T3 via microdialysis in the PVN increased plasma glucose as well as EGP without affecting circulating T3 levels. Selective hepatic sympathectomy prevented these effects, indicating that intrahypothalamic $\mathrm{T} 3$ regulates hepatic glucose production via a sympathetic pathway from the PVN [62, 63]. It is unknown at present whether this pathway is stimulated simultaneously with a cold challenge. Although the metabolic consequences of high SNS activity and high TH show considerable overlap, which may lead to the conclusion that these systems interact, this is not always the case [64]. Bachman et al. [64] showed that T3 treatment can correct the reduced heart rate and metabolic rate in $\beta$-adrenergic receptor-deficient mice, showing that there are SNS-independent routes for TH regulation of metabolism.

\section{T3 in the VMH Controls BAT Thermogenesis and} Liver Lipogenesis

There is increasing interest in the relationship between intrahypothalamic T3, increased sympathetic tone, and BAT activation. The first indication of a close correlation between $\mathrm{T} 3$ and sympathetic signaling to BAT came from mice with a mutant TRa1 which showed increased sympathetic activity and a hypermetabolic phenotype. Functional blockade of sympathetic signaling normalized BAT thermogenesis in these mice, suggesting a sympathetic regulation of BAT activation by $\mathrm{TH}$ [65]. This hypothesis was confirmed and elegantly expanded by subsequent studies from López et al. [66]. They showed increased SNS activity and increased thermogenic markers in BAT after administration of T3 in the VMH. The T3-induced sympathetic activation of BAT was further shown to be mediated by de novo lipogenesis and inactivation of AMP-activated protein kinase in the VMH. These effects were reversed by pharmacological blockade of $\beta_{3}$-adrenergic signaling [66]. A recent study by this group showed that 2 distinct signaling pathways downstream of AMP-activated protein kinase in the VMH regulate lipid metabolism in BAT and the liver, respectively. ICV T3 administration increased the lipogenic pathway in the liver via the parasympathetic nervous system while increasing the thermogenic program in BAT via the SNS [67]. Another observation in mice with a deficiency of the T3 inactivating enzyme D3 revealed a reduced body weight accompanied by smaller adipocyte sizes in WAT and BAT but unaltered Ucp 1 mRNA expression. It has been proposed that the hypermetabolic phenotype is secondary to increased $\mathrm{TH}$ action in the hypothalamus despite lower circulating $\mathrm{TH}$ concentrations [68]. Together, these studies demonstrated an important role of $\mathrm{TH}$ in the hypothalamus in regulation of BAT thermogenesis and liver lipid metabolism.

\section{T3 in the Anterior Hypothalamic Area Controls Cardiovascular Function}

$\mathrm{TH}$ status is also linked to cardiovascular function by direct effects of T3 on sino-atrial node firing and by indirect actions via the autonomic nervous system. Thus, hyperthyroid patients often display enhanced cardiac contractility, while hypothyroidism may induce reduced cardiac output and bradycardia [for review, see 69]. However, more recent studies on TH control of cardiovascular function revealed an additional central mechanism originating in the hypothalamus. Mittag et al. [70] reported that mice expressing the mutant TRa 1 exhibit a slight decrease in heart rate and a severely impaired cardiovascular response to stress or an environmental temperature challenge. This cardiac dysfunction in TRa1mutant mice was found to be due to an unbalanced sympatho-vagal tone from the brain [70]. Further studies indicated that a previously unknown population of parvalbuminergic neurons in the anterior hypothalamic area may be responsible for this dysregulation of heart function. Stereotaxic ablation of these neurons resulted in hypertension and temperature-dependent tachycardia. Interestingly, electrophysiological recordings indicated that these parvalbuminergic neurons display intrinsic temperature sensitivity while a majority is sensitive to TRH treatment, suggesting an interactive regulation between cardiovascular function and body temperature by TRH [71].

\section{T3 in the ARC Controls Feeding}

Thyrotoxicosis induced an increased food intake accompanied by increased hypothalamic neuropeptide $\mathrm{Y}$ mRNA and decreased hypothalamic proopiomelanocortin (POMC) mRNA expression [72]. Mice lacking the T3-inactivating enzyme D3, presumably leading to increased hypothalamic T3 levels, showed increased neuropeptide Y and decreased POMC gene expression [68]. Accordingly, direct T3 administration in the ARC resulted in increased feeding, a mechanism involving upregulation of the hypothalamic mammalian target of rapamycin (mTOR) signaling pathway [73]. Interestingly, $\mathrm{TH}$ induced orexigenic effects were linked with thermogenic pathways in the hypothalamus. Other studies showed that fasting increased hypothalamic D2 activity and, 
thereby, local T3 production. Elevated T3 in ARC appeared to accelerate UCP2-dependent mitochondrial uncoupling in neuropeptide Y/AgRP neurons, leading to consequent rebound feeding following food deprivation [74]. The observation that TH regulates POMC expression in the ARC may be relevant for cold-induced BAT thermogenesis as a recent study showed that cold exposure induces autophagy in hypothalamic POMC neurons, which is necessary to activate lipophagy in BAT and the liver through the sympathetic network favoring coldinduced thermogenesis [75].

\section{Acute versus Chronic Effects of}

Intrahypothalamic T3

The recently reported rapid effects of TH in the hypothalamus on energy metabolism prompted us to test this paradigm in a more chronic setting. This seemed relevant as some of the metabolic complications of thyrotoxicosis, including weight loss and bone loss, occur after long-term exposure to TH excess. We therefore aimed to develop a model for intrahypothalamic T3 administration in a more chronic setting to study metabolic effects of longer lasting T3 exposure. We designed an experimental protocol using T3-containing beeswax pellets that showed a stable T3 release $(\sim 5 \mathrm{nmol} / \mathrm{L})$ for 4 weeks in vitro. Bilateral implantation of these T3 pellets locally in the PVN or VMH of rats resulted in selectively increased T3 concentrations either in the PVN or VMH region for 28 days. Increased local T3 concentrations were shown to increase mRNA expression of T3-responsive genes. As expected, after placement of T3-containing pellets in the PVN, plasma T3 and T4 decreased, while there was no change in plasma $\mathrm{TH}$ after placement of T3-containing pellets in the VMH. Thus, our model is valid to selectively and chronically deliver $\mathrm{T} 3$ to specific hypothalamic nuclei [76]. However, surprisingly, body weight, food intake, and body temperature were not changed after T3 administration in the PVN or VMH for 28 days despite these nuclei-specific changes. In addition, no effects on energy expenditure, locomotor activity, or respiratory exchange rate were present upon 7 days of intrahypothalamic T3 administration. In view of the substantial metabolic effects by acute or chronic T3 injections $[66,67,77]$, our results imply that the effects of intrahypothalamic T3 on metabolism largely depend on the duration or the routes of treatment [78]. In line with our results, others showed that the effects of central $\mathrm{TH}$ administration on sleep were not only dose but also time dependent. An intermediate dose, but not a high dose, of T3 in the POA of euthyroid rats changed electro- encephalogram-defined sleep patterns. These central T3 effects on sleep occurred only after acute (h) but not chronic (days) T3 treatment $[79,80]$. An overview of the differential effects of acute and chronic intrahypothalamic T3 administration on energy metabolism is given in Figure 2.

\section{Conclusions}

For many decades, TH has been known to be critically involved in key metabolic processes including energy expenditure and heat preservation in response to cold. TH regulates both obligatory thermogenesis by increasing the basal metabolic rate and adaptive thermogenesis by targeting BAT, WAT, skeletal muscle, and skin blood flow. $\mathrm{TH}$ also regulates hepatic glucose production, cardiac function, and feeding, which are all key metabolic responses in cold defense. Recent and compelling evidence has shown that some of these effects of TH are mediated in part through the hypothalamus via the autonomic nervous system. In addition to $\mathrm{TH}$, hypothalamic TRH is also an important regulator of liver glucose metabolism, BAT thermogenesis, and other aspects of cold defense. However, differential metabolic effects observed depending on the animal model chosen, the timeframe of the experiments, and the $\mathrm{TH}$ administration route challenge us to further explore the central mechanisms involved in these neural effects of $\mathrm{TH}$.

\section{Disclosure Statement}

The authors declare no conflict of interests. 


\section{References}

1 Silva JE. The thermogenic effect of thyroid hormone and its clinical implications. Ann Intern Med. 2003 Aug;139(3):205-13.

2 Lahesmaa M, Orava J, Schalin-Jäntti C, Soinio M, Hannukainen JC, Noponen T, et al. Hyperthyroidism increases brown fat metabolism in humans. J Clin Endocrinol Metab. 2014 Jan;99(1):E28-35.

3 Gavrila A, Hasselgren PO, Glasgow A, Doyle AN, Lee AJ, Fox P, et al. Variable Cold-Induced Brown Adipose Tissue Response to Thyroid Hormone Status. Thyroid. 2017 Jan; 27(1): $1-10$

4 Joseph-Bravo P, Jaimes-Hoy L, Uribe RM, Charli JL. 60 YEARS OF NEUROENDOCRINOLOGY: TRH, the first hypophysiotropic releasing hormone isolated: control of the pituitary-thyroid axis. J Endocrinol. 2015 Aug; 226(2):T85-100.

5 Fliers E, Kalsbeek A, Boelen A: Beyond the fixed setpoint of the hypothalamus-pituitarythyroid axis. Eur J Endocrinol. 2014 171:R197-208.

6 van der Spek AH, Fliers E, Boelen A. The classic pathways of thyroid hormone metabolism. Mol Cell Endocrinol. 2017 Dec;458:29-38.

7 Larsen PR, Zavacki AM. The role of the iodothyronine deiodinases in the physiology and pathophysiology of thyroid hormone action. Eur Thyroid J. 2012;1(4):232-42.

8 Boelen A, Kwakkel J, Fliers E. Beyond low plasma T3: local thyroid hormone metabolism during inflammation and infection. Endocr Rev. 2011 Oct;32(5):670-93.

9 Boelen A, Wiersinga WM, Fliers E. Fastinginduced changes in the hypothalamus-pituitary-thyroid axis. Thyroid. 2008 Feb;18(2) 123-9.

10 Carvalho SD, Kimura ET, Bianco AC, Silva JE. Central role of brown adipose tissue thyroxine $5^{\prime}$-deiodinase on thyroid hormone-dependent thermogenic response to cold. Endocrinology. 1991 Apr;128(4):2149-59.

11 Zhang Z, Boelen A, Bisschop PH, Kalsbeek A, Fliers E. Hypothalamic effects of thyroid hormone. Mol Cell Endocrinol. 2017 Dec;458: 143-8.

12 Martínez-Sánchez N, Alvarez CV, Fernø J, Nogueiras R, Diéguez C, López M. Hypothalamic effects of thyroid hormones on metabolism. Best Pract Res Clin Endocrinol Metab. 2014 Oct;28(5):703-12.

13 Lechan RM, Fekete C. The TRH neuron: a hypothalamic integrator of energy metabolism. Prog Brain Res. 2006;153:209-35.

14 Sánchez E, Uribe RM, Corkidi G, Zoeller RT, Cisneros M, Zacarias M, et al. Differential responses of thyrotropin-releasing hormone (TRH) neurons to cold exposure or suckling indicate functional heterogeneity of the TRH system in the paraventricular nucleus of the rat hypothalamus. Neuroendocrinology. 2001 Dec;74(6):407-22.
15 Uribe RM, Redondo JL, Charli JL, JosephBravo P. Suckling and cold stress rapidly and transiently increase TRH mRNA in the paraventricular nucleus. Neuroendocrinology. 1993 Jul;58(1):140-5.

16 Cabral A, Valdivia S, Reynaldo M, Cyr NE, Nillni EA, Perello M. Short-term cold exposure activates TRH neurons exclusively in the hypothalamic paraventricular nucleus and raphe pallidus. Neurosci Lett. 2012 Jun;518(2):86-91.

17 Fliers E, Noppen NW, Wiersinga WM, Visser TJ, Swaab DF. Distribution of thyrotropinreleasing hormone (TRH)-containing cells and fibers in the human hypothalamus. J Comp Neurol. 1994 Dec;350(2):311-23.

18 Heinen CA, Zhang Z, Klieverik LP, de Wit TC, Poel E, Yaqub M, Boelen A, Kalsbeek A, Bisschop PH, van Trotsenburg ASP, Verberne HJ, Booij J, Fliers E: Effects of intravenous thyrotropin-releasing hormone on (18)F-fluorodeoxyglucose uptake in human brown adipose tissue: a randomized controlled trial. Eur J Endocrinol. 2018;179:31-38.

19 Perello M, Stuart RC, Vaslet CA, Nillni EA. Cold exposure increases the biosynthesis and proteolytic processing of prothyrotropin-releasing hormone in the hypothalamic paraventricular nucleus via beta-adrenoreceptors. Endocrinology. 2007 Oct;148(10):4952-64.

20 Zoeller RT, Kabeer N, Albers HE. Cold exposure elevates cellular levels of messenger ribonucleic acid encoding thyrotropin-releasing hormone in paraventricular nucleus despite elevated levels of thyroid hormones. Endocrinology. 1990 Dec;127(6):2955-62.

21 Zhang Z, Machado F, Zhao L, Heinen C, Foppen E, Ackermans MT, et al. Administration of thyrotropin-releasing hormone (TRH) in the hypothalamic paraventricular nucleus (PVN) of male rats mimics the metabolic cold defence response. Neuroendocrinology. 2018 Aug. https://doi.org/10.1159/000492785.

22 Silva JE. Thermogenic mechanisms and their hormonal regulation. Physiol Rev. 2006 Apr; 86(2):435-64

23 Morrison SF, Madden CJ, Tupone D. Central control of brown adipose tissue thermogenesis. Front Endocrinol (Lausanne). 2012 Jan; 3(5):3.

24 Weiner J, Hankir M, Heiker JT, Fenske W, Krause K. Thyroid hormones and browning of adipose tissue. Mol Cell Endocrinol. 2017 Dec;458:156-9.

25 Silva JE, Larsen PR. Adrenergic activation of triiodothyronine production in brown adipose tissue. Nature. 1983 Oct;305(5936): $712-3$.

26 de Jesus LA, Carvalho SD, Ribeiro MO, Schneider M, Kim SW, Harney JW, et al. The type 2 iodothyronine deiodinase is essential for adaptive thermogenesis in brown adipose tissue. J Clin Invest. 2001 Nov; 108(9):1379_ 85.
27 Bianco AC, Maia AL, da Silva WS, Christoffolete MA. Adaptive activation of thyroid hormone and energy expenditure. Biosci Rep. 2005 Jun-Aug;25(3-4):191-208.

28 Christoffolete MA, Linardi CC, de Jesus L, Ebina KN, Carvalho SD, Ribeiro MO, et al. Mice with targeted disruption of the Dio2 gene have cold-induced overexpression of the uncoupling protein 1 gene but fail to increase brown adipose tissue lipogenesis and adaptive thermogenesis. Diabetes. 2004 Mar;53(3): 577-84

29 Branco M, Ribeiro M, Negrão N, Bianco AC. 3,5,3'-Triiodothyronine actively stimulates UCP in brown fat under minimal sympathetic activity. Am J Physiol. 1999 Jan;276(1 Pt 1):E179-87.

30 Solmonson A, Mills EM. Uncoupling Proteins and the Molecular Mechanisms of Thyroid Thermogenesis. Endocrinology. 2016 Feb;157(2):455-62.

31 Ribeiro MO, Carvalho SD, Schultz JJ, Chiellini G, Scanlan TS, Bianco AC, et al. Thyroid hormone-sympathetic interaction and adaptive thermogenesis are thyroid hormone receptor isoform-specific. J Clin Invest. 2001 Jul;108(1):97-105.

32 Shu L, Hoo RL, Wu X, Pan Y, Lee IP, Cheong LY, et al. A-FABP mediates adaptive thermogenesis by promoting intracellular activation of thyroid hormones in brown adipocytes. Nat Commun. 2017 Jan;8:14147.

33 Lee JY, Takahashi N, Yasubuchi M, Kim YI, Hashizaki H, Kim MJ, et al. Triiodothyronine induces UCP-1 expression and mitochondrial biogenesis in human adipocytes. Am J Physiol Cell Physiol. 2012 Jan;302(2):C46372.

34 Lin JZ, Martagón AJ, Cimini SL, Gonzalez DD, Tinkey DW, Biter A, et al. Pharmacological Activation of Thyroid Hormone Receptors Elicits a Functional Conversion of White to Brown Fat. Cell Reports. 2015 Nov;13(8): 1528-37.

35 Martínez-Sánchez N, Moreno-Navarrete JM, Contreras C, Rial-Pensado E, Fernø J, Nogueiras $\mathrm{R}$, et al. Thyroid hormones induce browning of white fat. J Endocrinol. 2017 Feb; 232(2):351-62.

36 Miao Y, Wu W, Dai Y, Maneix L, Huang B, Warner $\mathrm{M}$, et al. Liver $\mathrm{X}$ receptor $\beta$ controls thyroid hormone feedback in the brain and regulates browning of subcutaneous white adipose tissue. Proc Natl Acad Sci USA. 2015 Nov;112(45):14006-11.

37 Korach-André M, Archer A, Barros RP, Parini $\mathrm{P}$, Gustafsson JA. Both liver-X receptor (LXR) isoforms control energy expenditure by regulating brown adipose tissue activity. Proc Natl Acad Sci USA. 2011 Jan;108(1): 403-8. 
38 Weiner J, Kranz M, Klöting N, Kunath A, Steinhoff K, Rijntjes E, et al. Thyroid hormone status defines brown adipose tissue activity and browning of white adipose tissues in mice. Sci Rep. 2016 Dec;6(1):38124.

39 Schulz TJ, Huang P, Huang TL, Xue R, McDougall LE, Townsend KL, et al. Brown-fat paucity due to impaired BMP signalling induces compensatory browning of white fat. Nature. 2013 Mar;495(7441):379-83.

40 Gong DW, He Y, Karas M, Reitman M. Uncoupling protein-3 is a mediator of thermogenesis regulated by thyroid hormone, beta3adrenergic agonists, and leptin. J Biol Chem. 1997 Sep;272(39):24129-32.

41 Simonides WS, Thelen MH, van der Linden CG, Muller A, van Hardeveld C. Mechanism of thyroid-hormone regulated expression of the SERCA genes in skeletal muscle: implications for thermogenesis. Biosci Rep. 2001 Apr;21(2):139-54.

42 Gong DW, Monemdjou S, Gavrilova O, Leon LR, Marcus-Samuels B, Chou CJ, et al. Lack of obesity and normal response to fasting and thyroid hormone in mice lacking uncoupling protein-3. J Biol Chem. 2000 May;275(21): 16251-7.

43 Ootsuka Y, Tanaka M. Control of cutaneous blood flow by central nervous system. Temperature (Austin). 2015 Jul;2(3):392-405.

44 Warner A, Rahman A, Solsjö P, Gottschling $\mathrm{K}$, Davis B, Vennström B, et al. Inappropriate heat dissipation ignites brown fat thermogenesis in mice with a mutant thyroid hormone receptor a1. Proc Natl Acad Sci USA. 2013 Oct;110(40):16241-6.

45 Shintani M, Tamura Y, Monden M, Shiomi $\mathrm{H}$. Thyrotropin-releasing hormone induced thermogenesis in Syrian hamsters: site of action and receptor subtype. Brain Res. 2005 Mar; 1039(1-2):22-9.

46 Salzman SK, Beckman AL. Effects of thyrotropin releasing hormone on hypothalamic thermosensitive neurons of the rat. Brain Res Bull. 1981 Sep;7(3):325-32.

47 Chi ML, Lin MT. Involvement of adrenergic receptor mechanisms within hypothalamus in the fever induced by amphetamine and thyrotropin-releasing hormone in the rat. J Neural Transm (Vienna). 1983;58(3-4):213-22.

48 Hori T, Yamasaki M, Asami T, Koga H, Kiyohara T. Responses of anterior hypothalamicpreoptic thermosensitive neurons to thyrotropin releasing hormone and cyclo(HisPro). Neuropharmacology. 1988 Sep;27(9): 895-901.

49 Ishikawa K, Suzuki M. Antagonism by thyrotropin-releasing hormone (TRH) of pentobarbital-induced hypothermia in rats with brain lesions. Experientia. 1986 Sep;42(9): 1029-31.
50 Fiedler J, Jara P, Luza S, Dorfman M, Grouselle $\mathrm{D}$, Rage F, et al. Cold stress induces metabolic activation of thyrotrophin-releasing hormone-synthesising neurones in the magnocellular division of the hypothalamic paraventricular nucleus and concomitantly changes ovarian sympathetic activity parameters. J Neuroendocrinol. 2006 May;18(5): 367-76.

51 Sved AF, Cano G, Card JP. Neuroanatomical specificity of the circuits controlling sympathetic outflow to different targets. Clin Exp Pharmacol Physiol. 2001 Jan-Feb;28(1-2): $115-9$.

52 Cano G, Passerin AM, Schiltz JC, Card JP, Morrison SF, Sved AF. Anatomical substrates for the central control of sympathetic outflow to interscapular adipose tissue during cold exposure. J Comp Neurol. 2003 Jun;460(3):30326.

53 Yamada M, Satoh T, Mori M. Mice lacking the thyrotropin-releasing hormone gene: what do they tell us? Thyroid. 2003 Dec;13(12):111121.

54 Kalsbeek A, Bruinstroop E, Yi CX, Klieverik LP, La Fleur SE, Fliers E. Hypothalamic control of energy metabolism via the autonomic nervous system. Ann N Y Acad Sci. 2010 Nov; 1212(1):114-29.

55 Mayerl S, Müller J, Bauer R, Richert S, Kassmann CM, Darras VM, et al. Transporters MCT8 and OATP1C1 maintain murine brain thyroid hormone homeostasis. J Clin Invest. 2014 May;124(5):1987-99.

56 Lechan RM, Fekete C. Role of thyroid hormone deiodination in the hypothalamus. Thyroid. 2005 Aug;15(8):883-97.

57 Wallis K, Dudazy S, van Hogerlinden M, Nordström K, Mittag J, Vennström B. The thyroid hormone receptor alphal protein is expressed in embryonic postmitotic neurons and persists in most adult neurons. Mol Endocrinol. 2010 Oct;24(10):1904-16.

58 Dimitriadis GD, Raptis SA. Thyroid hormone excess and glucose intolerance. Exp Clin Endocrinol Diabetes. 2001;109 Suppl 2:S225-39.

59 Klieverik LP, Coomans CP, Endert E, Sauerwein HP, Havekes LM, Voshol PJ, et al. Thyroid hormone effects on whole-body energy homeostasis and tissue-specific fatty acid uptake in vivo. Endocrinology. 2009 Dec; 150(12):5639-48.

60 Eustatia-Rutten CF, Corssmit EP, Heemstra KA, Smit JW, Schoemaker RC, Romijn JA, et al. Autonomic nervous system function in chronic exogenous subclinical thyrotoxicosis and the effect of restoring euthyroidism. J Clin Endocrinol Metab. 2008 Jul;93(7):283541.

61 Klieverik LP, Sauerwein HP, Ackermans MT, Boelen A, Kalsbeek A, Fliers E. Effects of thyrotoxicosis and selective hepatic autonomic denervation on hepatic glucose metabolism in rats. Am J Physiol Endocrinol Metab. 2008 Mar;294(3):E513-20.
62 Klieverik LP, Janssen SF, van Riel A, Foppen E, Bisschop PH, Serlie MJ, et al. Thyroid hormone modulates glucose production via a sympathetic pathway from the hypothalamic paraventricular nucleus to the liver. Proc Natl Acad Sci USA. 2009 Apr;106(14):5966-71.

63 Fliers E, Klieverik LP, Kalsbeek A. Novel neural pathways for metabolic effects of thyroid hormone. Trends Endocrinol Metab. 2010 Apr;21(4):230-6.

64 Bachman ES, Hampton TG, Dhillon $H$, Amende I, Wang J, Morgan JP, et al. The metabolic and cardiovascular effects of hyperthyroidism are largely independent of beta-adrenergic stimulation. Endocrinology. 2004 Jun;145(6):2767-74

65 Sjögren M, Alkemade A, Mittag J, Nordström $\mathrm{K}$, Katz A, Rozell B, et al. Hypermetabolism in mice caused by the central action of an unliganded thyroid hormone receptor alpha1. EMBO J. 2007 Oct;26(21):4535-45.

66 López M, Varela L, Vázquez MJ, RodríguezCuenca S, González CR, Velagapudi VR, et al. Hypothalamic AMPK and fatty acid metabolism mediate thyroid regulation of energy balance. Nat Med. 2010 Sep;16(9):1001-8.

67 Martinez-Sanchez N, Seoane-Collazo P, Contreras C, Varela L, Villarroya J, Rial-Pensado E, Buque X, Aurrekoetxea I, Delgado TC, Vazquez-Martinez R, Gonzalez-Garcia I, Roa J, Whittle AJ, Gomez-Santos B, Velagapudi V, Tung YCL, Morgan DA, Voshol PJ, Martinez de Morentin PB, Lopez-Gonzalez T, LinaresPose L, Gonzalez F, Chatterjee K, Sobrino T, Medina-Gomez G, Davis RJ, Casals N, Oresic M, Coll AP, Vidal-Puig A, Mittag J, TenaSempere M, Malagon MM, Dieguez C, Martinez-Chantar ML, Aspichueta P, Rahmouni K, Nogueiras R, Sabio G, Villarroya F, Lopez M. Hypothalamic AMPK-ER stress-JNK1 axis mediates the central actions of thyroid hormones on energy balance. Cell Metab. 2017 Jul;26(1):212-229.e12.

68 Wu Z, Martinez ME, St Germain DL, Hernandez A. Type 3 deiodinase role on central thyroid hormone action affects the leptin-melanocortin system and circadian activity. Endocrinology. 2017 Feb;158(2):419-30.

69 Klein I, Danzi S. Thyroid Disease and the Heart. Curr Probl Cardiol. 2016 Feb;41(2): 65-92.

70 Mittag J, Wallis K, Vennström B. Physiological consequences of the TRalphal aporeceptor state. Heart Fail Rev. 2010 Mar;15(2):1115.

71 Mittag J, Lyons DJ, Sällström J, Vujovic M, Dudazy-Gralla S, Warner A, et al. Thyroid hormone is required for hypothalamic neurons regulating cardiovascular functions. J Clin Invest. 2013 Jan;123(1):509-16. 
72 Ishii S, Kamegai J, Tamura H, Shimizu T, Sugihara H, Oikawa S. Triiodothyronine (T3) stimulates food intake via enhanced hypothalamic AMP-activated kinase activity. Regul Pept. 2008 Nov;151(1-3):164-9.

73 Varela L, Martínez-Sánchez N, Gallego R, Vázquez MJ, Roa J, Gándara M, et al. Hypothalamic mTOR pathway mediates thyroid hormone-induced hyperphagia in hyperthyroidism. J Pathol. 2012 Jun;227(2):209-22.

74 Coppola A, Liu ZW, Andrews ZB, Paradis E, Roy MC, Friedman JM, et al. A central thermogenic-like mechanism in feeding regulation: an interplay between arcuate nucleus T3 and UCP2. Cell Metab. 2007 Jan;5(1):21-33.
75 Martinez-Lopez N, Garcia-Macia M, Sahu S, Athonvarangkul D, Liebling E, Merlo P, et al. Autophagy in the CNS and Periphery Coordinate Lipophagy and Lipolysis in the Brown Adipose Tissue and Liver. Cell Metab. 2016 Jan;23(1):113-27.

76 Zhang Z, Bisschop PH, Foppen E, van Beeren HC, Kalsbeek A, Boelen A, et al. A model for chronic, intrahypothalamic thyroid hormone administration in rats. J Endocrinol. 2016 Apr;229(1):37-45.

77 Alvarez-Crespo M, Csikasz RI, MartínezSánchez N, Diéguez C, Cannon B, Nedergaard J, et al. Essential role of UCP1 modulating the central effects of thyroid hormones on energy balance. Mol Metab. 2016 Feb;5(4): 271-82.
78 Zhang Z, Foppen E, Su Y, Bisschop PH, Kalsbeek A, Fliers E, et al. Metabolic Effects of Chronic T3 Administration in the Hypothalamic Paraventricular and Ventromedial Nucleus in Male Rats. Endocrinology. 2016 Oct; 157(10):4076-85.

79 Martin JV, Giannopoulos PF, Moffett SX, James TD. Effects of acute microinjections of thyroid hormone to the preoptic region of euthyroid adult male rats on sleep and motor activity. Brain Res. 2013 Jun;1516:45-54.

80 Moffett SX, Giannopoulos PF, James TD Martin JV. Effects of acute microinjections of thyroid hormone to the preoptic region of hypothyroid adult male rats on sleep, motor activity and body temperature. Brain Res. 2013 Jun;1516:55-65. 